\title{
Usefulness of Basic Fibroblast Growth Factor (bFGF) Loaded Dissolving Microneedles for Local Therapy of Skin Wounds
}

\author{
Kanji Takada $^{1}$, Yukako Ito ${ }^{1}$, Kengo Matsumoto ${ }^{1}$, Yuka Sato ${ }^{1}$, Maimi Nishio ${ }^{1}$, Yurie Tadano ${ }^{1}$, \\ Yuri Kamei $^{1}$, Yutaro Takemura ${ }^{1}$, Nana Inoue ${ }^{2}$, Yoshiki Akasaka ${ }^{3}$, Ichiro Ono ${ }^{4}$ \\ ${ }^{1}$ Department of Pharmacokinetics, Kyoto Pharmaceutical University, Yamashina-Ku, Kyoto, Japan; ${ }^{2}$ BioSerenTach Inc., Shimogyo- \\ $\mathrm{Ku}$, Kyoto, Japan; ${ }^{3}$ Devision of Chronic Inflammatory Diseases, Advanced Medical Research Center, Toho University Graduate \\ School of Medicine, Ota-Ku, Tokyo, Japan; ${ }^{4}$ Department of Dermatology, Sapporo Medical University School of Medicine, Chuo- \\ $\mathrm{Ku}$, Sapporo, Japan. \\ Email: takada@mb.kyoto-phu.ac.jp
}

Received May $17^{\text {th }}, 2013$; revised June $14^{\text {th }}, 2013$; accepted June $25^{\text {th }}, 2013$

Copyright (C) 2013 Kanji Takada et al. This is an open access article distributed under the Creative Commons Attribution License, which permits unrestricted use, distribution, and reproduction in any medium, provided the original work is properly cited.

\begin{abstract}
Purpose: The usefulness of dissolving microneedles (DMs) for local skin therapy by basic fibroblast growth factor (bFGF) was studied in rats. Methods: We prepared four kinds of bFGF-loaded DMs, approximately $500 \mu \mathrm{m}$ length and $300 \mu \mathrm{m}$ diameter at the bottom. Long-term stability and dissolution studies were performed by HPLC method. Pharmacokinetic and pharmacological evaluations were performed after administration of bFGF loaded DMs to rats. Results: The bFGF contents were $2.15 \pm 0.07,1.07 \pm 0.04,0.56 \pm 0.07$ and $0.12 \pm 0.03 \mu \mathrm{g}$. The $100.2 \pm 3.4 \%, 100.2 \pm 3.3 \%$, $99.3 \pm 1.4 \%$ and $100.4 \pm 3.0 \%$ of bFGF were recovered after 1,3 and 6 months and 1 year incubation at $40^{\circ} \mathrm{C}$. The bFGF was released from DMs within 5 min. In a pharmacokinetic study using 2.0 and $1.0 \mu \mathrm{g}$ bFGF-loaded DMs, no systemic exposure of bFGF was detected. The initial bFGF concentrations in the rat skin tissue after administration of bFGF-loaded DMs to the hair-removed rat abdominal skin were $510.2 \pm 20.1 \mathrm{ng} / \mathrm{g}$ wet weight for $2 \mu \mathrm{g}$ bFGF DMs and $264.2 \pm 56.5 \mathrm{ng} / \mathrm{g}$ wet weight for $1 \mu \mathrm{g}$ DMs, declining slowly thereafter to $226.3 \pm 33.5$ and $105.1 \pm 27.4 \mathrm{ng} / \mathrm{g}$ wet weight at $6 \mathrm{hr}$ after administration. Good dose-dependency was observed. Pharmacological evaluation of bFGF-loaded DMs of 2.0, 1.0, 0.5, and 0.1 $\mu \mathrm{g}$, in the wound healing rat model, all used DMs, but $0.1 \mu \mathrm{g}$ DMs, showed good healing effects. Considered collectively, these results suggest the usefulness of bFGF-loaded DMs for local therapy of skin wound disease.
\end{abstract}

Keywords: Basic Fibroblast Growth Factor (bFGF); Dissolving Microneedles (DMs); Transdermal Delivery; Wound Healing; Rats

\section{Introduction}

Dissolving microneedles (DMs) are a novel transdermal drug delivery system (TDDS) for peptide/protein drugs, where drugs are absorbed from the skin into the systemic circulation with high absorption efficiency [1]. When DMs applied with biopharmaceuticals having poor permeability through the skin, high bioavailabilities (BAs) and/or pharmacological availabilities (PAs) have been obtained: $98.1 \%$ for insulin in rats [2] and $72.8 \%-89.9 \%$ for recombinant human growth hormone (rhGH) in rats [3], and $65.9 \%-69.0 \%$ for erythropoietin (EPO) in dogs [4]. The relative BA of interferon (IFN) against subcutaneous injection of IFN solution was $79.9 \%-117.8 \%$ in rats [5]. In those studies, DMs were designed to deliver peptide/proteins percutaneously to the systemic circulation and to elucidate their systemic effects. Microneedles (MNs) of several kinds have been developed: surfacecoated MNs, hollow type MNs, and solid type MNs [6-8], which can be made of metal, plastic or silicon. Coated type MNs physically break the skin barrier and deliver the coated drug to the epidermal and dermal regions of the skin. Hollow type and solid type MNs make microconduits on the skin surface region, through which the drug is delivered as a solution or ointment with a micropump or sponge. Because the materials used to produce those MNs are not used in pharmaceutical preparations, 
those MNs do not belong to the category of pharmaceutical preparation. In contrast, DMs are made of watersoluble thread-forming biopolymer such as chondroitin sulfate, dextran, hyaluronic acid and albumin that are used as the base polymer [2-5] and drug is formulated as a solid dispersion with those base polymers. Using microfabrication technology, 200 - $300 \mathrm{DMs}$ are made on a chip of 15 - $20 \mathrm{~mm}$ diameter as arrays [1]. Each DM has approximately $500 \mu \mathrm{m}$ length and $300 \mu \mathrm{m}$ diameter at its base.

Human skin comprises three layers: the stratum corneum, epidermis, and dermis. The first is the $10-15 \mu \mathrm{m}$ thick outer layer; it is dead tissue. The stratum corneum has a strong primary barrier function against exogenous compounds, including drugs. The second barrier is the viable epidermis $(100-150 \mu \mathrm{m})$, which contains tissues such as living cells. However, no blood vessels exist in the epidermis. To increase the skin permeability of drugs, numerous approaches have been attempted using chemical enhancers, electric fields, ultrasound, and thermal methods [9-13]. However, these TDDS' success has remained limited because of the strong barrier function of the skin: the membrane permeability of drugs through the skin is extremely low. The DMs have sufficient hardness to penetrate into the skin and deliver the formulated drug to the epidermis after the base polymer dissolves immediately in the skin. We have conducted feasibility studies of DMs to assess the systemic delivery of poor membrane permeable drugs, especially biopharmaceuticals [2-5]. However, DMs are also applicable for the local delivery of drugs used for the therapy of skin diseases.

Basic fibroblast growth factor (bFGF), which is released during the early stage of the wound healing process, promotes the migration, proliferation, proteolytic enzyme production, and capillary growth of endothelial cells [14-18]. In fact, bFGF is used clinically for the bedsore therapy. However, when bFGF was applied as an anti-aging therapy of the skin, good clinical results were obtained, where bFGF solution was injected to the face skin [19-21]. However, before injection of a bFGF solution, local anesthesia is necessary. On the other hand, the important benefit of DMs is their pain-free or less-painful administration of drug to the skin. Therefore, in this report, DMs were applied to bFGF for local skin therapy in acute incisional wounds and their efficiency was evaluated in rat experiments.

\section{Materials and Methods}

\subsection{Materials}

We obtained bFGF from Fibrasto Spray ${ }^{\mathrm{TM}}$ (Kaken Pharmaceutical Co., Ltd., Tokyo, Japan) as a lyophilized product. Coomassie brilliant blue (BB), sodium chondroitin sulfate, cellulose acetate (CA) and hydroxypropyl cellulose (HPC) were obtained from Wako Pure Chemical Industries Ltd. (Osaka, Japan). Evans blue and dextran were obtained from Nacalai Tesque Inc. (Kyoto, Japan). An R \& D Systems bFGF ELISA assay kit was obtained from Cosmo Bio Co. Ltd. (Tokyo, Japan). Male Wistar Hannover rats used in the study were obtained from Japan SLC, Inc. (Hamamatsu, Japan). A standard solid-meal commercial food (LabDiet ${ }^{\mathrm{TM}}$; Nippon Nousan, Yokohama, Japan) was used. All other materials used were of reagent grade and were used as received.

\subsection{Preparation of DM Array Chip}

The BB solution and evans blue solution were prepared by dissolving $1.0 \mathrm{mg}$ of $\mathrm{BB}$ and evans blue with $3 \mathrm{ml}$ of distilled water. To the mixture of bFGF $(10.0-1.0 \mathrm{mg})$, sodium chondroitin sulfate $(15.0 \mathrm{mg})$ and dextran $(10.0$ $\mathrm{mg}), 60 \mu \mathrm{l}$ of BB solution or evans blue solution was added and dissolved. After obtaining the hydrogel, the glue was degassed under reduced pressure and then dispensed into a mold containing 225 inverted cone-shaped wells with area of $1.0 \mathrm{~cm}^{2}$. Each well was $500 \mu \mathrm{m}$ deep with $300 \mu \mathrm{m}$ diameter at its top. The mold was covered with a $300 \mathrm{~g}$ steel plate, and the drug glue was filled into the wells. After the plate was removed, glue consisting of $15 \mathrm{mg}$ of chondroitin sulfate and $25 \mathrm{ml}$ of distilled water was painted over a chip that had been prepared using a tabletting machine (Handtab-100; Ichihashi Seki, Kyoto, Japan) with the mixture of CA and HPC. The $17 \mathrm{~mm}$ diameter chip was $2.5 \mathrm{~mm}$ thick. After drying under pressure of a stainless steel plate for $3 \mathrm{~h}$, the plate was removed and DMs were obtained by detaching them with a supporting material. Placebo DMs were prepared using the same method, but bFGF was not added to them.

\subsection{Microscopic Observation of DMs}

The bFGF-loaded DM array chip stained with BB was observed under normal light using a digital videomicroscope (VH-5500; Keyence Co., Osaka, Japan).

\section{4. bFGF Contents in DMs}

The bFGF was extracted from a chip having DMs with $2.0 \mathrm{ml}$ of phosphate buffer, $\mathrm{pH} 7.4$, by slow agitation for $10 \mathrm{~min}$ at $4^{\circ} \mathrm{C}$. The obtained extract was centrifuged at 13,000 rpm for $5 \mathrm{~min}$ at $8^{\circ} \mathrm{C}$ (Kubota 3700; Kubota Corp., Tokyo, Japan). The supernate was separated from the debris and $100 \mu \mathrm{l}$ of the supernate was injected to the HPLC system.

\subsection{HPLC Assay Method of bFGF}

The $50-100 \mu$ of the bFGF solution was injected to the HPLC system composed of LC-10A pump (Shimadzu Corp., Kyoto, Japan) and UV detector (SPD-10A; Shi- 
madzu Corp., Kyoto, Japan). The used column was a GPC column, TSK-GEL G3000SW column, $7.5 \mathrm{~mm} \times$ $300 \mathrm{~mm}$, with TSK-GUARD column SW, $7.5 \mathrm{~mm} \times 75$ mm (Tosoh Corp., Tokyo, Japan). The mobile phase consisted of $0.2 \mathrm{M}$ phosphate buffer, $\mathrm{pH}$ 6.8. The flow rate was $1.0 \mathrm{ml} / \mathrm{min}$. The column temperature was $30^{\circ} \mathrm{C}$. The detection wavelength of bFGF was $280 \mathrm{~nm}$.

\subsection{In Vitro Dissolution Experiment}

An in vitro dissolution experiment was performed using DM array chip with $3.0 \mathrm{ml}$ of phosphate buffered saline (PBS), $\mathrm{pH} 7.4$, as the dissolution medium at $37^{\circ} \mathrm{C}$. To determine the amount of $\mathrm{bFGF}$ released from DM array chip, $0.1 \mathrm{ml}$ of the dissolution medium was collected for the assay at the predetermined time, 0, 1.0, 2.0, 3.0, 5.0, $8.0,10.0,15.0$ and $30 \mathrm{~min}$, thereafter replaced with fresh dissolution medium that had been degassed before. The cumulative released amount of bFGF from DM array chip was defined by the following equation.

$$
\text { Cumulative amount released }=\left(\sum_{t=0}^{t} M_{t} / M_{30 \min }\right) \times 100 \%
$$

In that equation, Mt was the amount of bFGF dissolved at time $\mathrm{t}$ and $\mathrm{M}_{30 \mathrm{~min}}$ was the dissolved amount of bFGF at 30 min after the start of the dissolution experiment.

\subsection{Stability Experiment}

DM array tips were kept for 1, 3, 6 and 12 months under four temperature conditions: $-80,4,23$, and $40^{\circ} \mathrm{C}$. Thereafter, DM array chips were dissolved with $2.0 \mathrm{ml}$ of

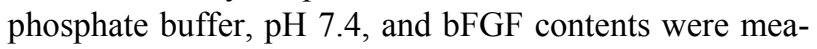
sured using HPLC method.

\subsection{In Vivo Absorption Experiments in Rats}

Male Wistar Hannover rats, $338 \pm 17$ g, were anesthetized with intraperitoneal (ip) injection of sodium pentobarbital, $50 \mathrm{mg} / \mathrm{kg}$. One group consisted of $3-4$ rats. At $5 \mathrm{~min}$ before drug administration, $0.25 \mathrm{ml}$ of blank blood sample was obtained from the left jugular vein with a heparinized syringe. The hair on the abdominal region was removed with a shaver. The bFGF-loaded DM array chip was administered to the skin by pressing with an applicator for $3.0 \mathrm{~min}$. At 15 and $30 \mathrm{~min}$ and at 1, 2, and $3 \mathrm{hr}$ after administration, $0.2 \mathrm{ml}$ blood samples were collected from the left jugular vein using a heparinized syringe. By centrifuging at $12,000 \mathrm{rpm}$ for $10 \mathrm{~min}$ at $4^{\circ} \mathrm{C}$ (Kubota 1700; Kubota, Tokyo, Japan), $100 \mu$ plasma samples were obtained. The resultant plasma samples were stored at $-80^{\circ} \mathrm{C}$ until analysis.

For the subcutaneous (sc) injection experiment, bFGF solution was injected to another group of rats, 1.0 and 2.0
IU. After a $0.25-\mathrm{ml}$ blank blood sample was obtained from the left jugular vein, blood samples of $0.2 \mathrm{ml}$ were obtained for $4 \mathrm{hr}$ and plasma samples were obtained after centrifugation. All these plasma samples were immediately frozen in a deep freezer at $-80^{\circ} \mathrm{C}$ until analysis.

In another group of rats, the kinetics of bFGF in the administered skin tissue was studied. After administration of the bFGF-loaded DM array chip to the rat skin, the skin tissue was removed at 1,2, 3, 4, 5 and $6 \mathrm{hr}$ and was homogenized with ten times the volume of PBS. The obtained homogenate was centrifuged at 12,000 rpm with a centrifuge for $10 \mathrm{~min}$. The obtained supernate was used for bFGF contents by ELISA assay.

\subsection{Experimental Therapy of Incisional Wounds on the Rat Skin}

Male Wistar Hannover rats, $321 \pm 13 \mathrm{~g}$, were anesthetized with an ip injection of sodium pentobarbital. One group consisted of $5-6$ rats. The hair on the abdominal region was removed using a shaver. After a wound was created using a surgical scalpel, the skin was sutured with three dots. Then the abdominal skin was covered with tape. The rats were kept in a cage for three days with food and water given ad libitum. At 3 days after surgery, bFGF-loaded DM array chip was administered to the incisional wound formed on the abdominal skin. Thereafter the state of the wound was monitored for 4 days, with images recorded using a digital camera (Nikon D500; Nikon Corp., Tokyo, Japan).

All animal protocols were approved by the institutional animal care and use committee. Experiments were conducted in accordance with the Guidelines for Animal Experimentation, Kyoto Pharmaceutical University.

\subsection{Plasma bFGF Assay with ELISA Method}

The plasma bFGF levels were measured using an enzyme immunoassay (EIA) method using an Immunoassay Kit (R\&D Systems, Minneapolis, USA). The method uses a quantitative sandwich enzyme immunoassay technique. The bFGF concentration of the plasma samples was determined against a standard curve of bFGF in rat plasma. The variability of the assay was evaluated using data obtained for bFGF quality control samples prepared in rat plasma and the standard curve. The validation parameters of precision (CV less than 15\%) and accuracy (recovery of $\pm 20 \%$ ) were acceptable and the lower limit of quantitation (LOQ) was $30.0 \mathrm{pg} / \mathrm{ml}$. A plate-shaker (Titramax 101; Heidolph Instruments $\mathrm{GmbH}$ and Co., KG, Germany) and a plate washer (Dia-washer II; Dia-Iatron Co. Ltd., USA) were used. Absorbance was measured at 450 $\mathrm{nm}$ using a microplate reader (MTP-300; Corona Electric Co. Ltd., Japan). 


\subsection{Statistics}

All values are expressed as their mean \pm S.E. Statistically significant differences were inferred for $\mathrm{p}<0.05$ (Student's unpaired t-test).

\section{Results}

\subsection{Physicochemical Characteristics of Prepared DMs}

Four kinds of bFGF-loaded DM array chips were prepared as presented in Figure 1, where the location of bFGF in the DMs was suggested by blue color due to the addition of $\mathrm{BB}$, because $\mathrm{BB}$ made a uniform coloring of the bFGF filled tip portion of DM than evans blue. As the same mold was used to prepare DM array chips of four kinds, the shapes and sizes of the DM array chips were fundamentally equal. Table 1 presents the physicochemical properties of the used DM array chips. The mean lengths of the DMs were $481 \pm 8(\mathrm{SE}), 489 \pm 3$, $472 \pm 5$, and $487 \pm 9 \mu \mathrm{m}$. Their basement diameters were, respectively, $286 \pm 6,289 \pm 3,284 \pm 6$, and $288 \pm 7 \mu \mathrm{m}$. The formulated amounts of bFGF were measured using HPLC assay with GPC mode. The bFGF contents of the

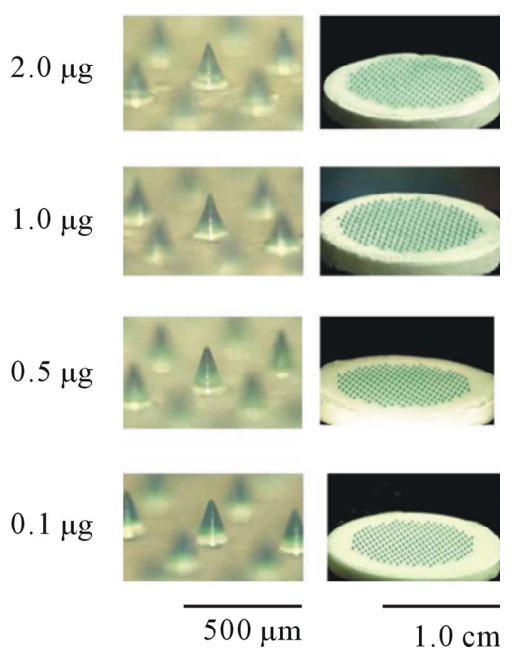

Figure 1. Dissolving microneedles and their array chips containing $0.1-2.0 \mu \mathrm{g}$ bFGF. The tip portion where bFGF was formulated was stained with brilliant blue.

Table 1. Physicochemical properties of bFGF DM array chips.

\begin{tabular}{cccc}
\hline Type & Amount of bFGF & Length $(\mu \mathrm{m})$ & $\begin{array}{c}\text { Diameter of } \\
\text { basement }(\mu \mathrm{m})\end{array}$ \\
\hline $2.0 \mu \mathrm{g}$ & $2.15 \pm 0.07$ & $481 \pm 8$ & $286 \pm 6$ \\
$1.0 \mu \mathrm{g}$ & $1.07 \pm 0.04$ & $489 \pm 3$ & $289 \pm 3$ \\
$0.5 \mu \mathrm{g}$ & $0.56 \pm 0.07$ & $472 \pm 5$ & $284 \pm 6$ \\
$0.1 \mu \mathrm{g}$ & $0.12 \pm 0.03$ & $487 \pm 9$ & $288 \pm 7$ \\
\hline
\end{tabular}

Each value shows the mean \pm S.D. $(n=4-6)$. four kinds of DM array chips were measured to be, respectively, $2.15 \pm 0.07(\mathrm{SE}), 1.07 \pm 0.04,0.56 \pm 0.07$, and $0.12 \pm 0.03 \mu \mathrm{g}$.

The long term stability studies on bFGF loaded DM array chips were performed for 1, 3 and 6 months and 1 year. The results are shown in Table 2 , where bFGF contents were also assayed using HPLC method. The remaining amounts of bFGF in DMs are shown as the relative percentage against DMs that were stored at $-80^{\circ} \mathrm{C}$ for individual temperature. High amounts of bFGF were recovered after incubation. Especially, $101.3 \pm 3.4 \%$ $\left(4^{\circ} \mathrm{C}\right), 101.1 \pm 2.9 \%\left(23^{\circ} \mathrm{C}\right)$, and $100.4 \pm 3.0\left(40^{\circ} \mathrm{C}\right) \%$ of bFGF were detected after incubation under three different temperatures for 1 year. Those results suggest that bFGF was very stable in DMs, because bFGF existed in DMs as solid preparation. A dissolution experiment was conducted with the bFGF DM array chips. The representative dissolution pattern is depicted in Figure 2, where DM array chips of which mean bFGF content was 2.15 $\mu \mathrm{g}$ were used. The dissolution rate of bFGF was so high that the formulated bFGF was released completely from DM array chips within 5 min.

\subsection{Effect of bFGF Loaded DMs on Incisional Wound Recovery in Rats}

Pharmacological evaluation of bFGF loaded DMs was

Table 2. Long-term stability of bFGF in DMs.

\begin{tabular}{cccc}
\hline \multirow{2}{*}{ Period } & \multicolumn{3}{c}{ Temperature } \\
\cline { 2 - 4 } & $4^{\circ} \mathrm{C}$ & $23^{\circ} \mathrm{C}$ & $40^{\circ} \mathrm{C}$ \\
\hline 1 week & $101.6 \pm 4.7 \%$ & $100.9 \pm 8.8 \%$ & $103.3 \pm 4.7 \%$ \\
1 month & $100.7 \pm 2.0 \%$ & $98.7 \pm 4.9 \%$ & $102.8 \pm 2.7 \%$ \\
3 months & $98.7 \pm 7.1 \%$ & $99.0 \pm 7.0 \%$ & $100.7 \pm 7.6 \%$ \\
6 months & $98.8 \pm 2.6 \%$ & $99.0 \pm 1.2 \%$ & $99.3 \pm 1.4 \%$ \\
1 year & $101.3 \pm 3.4 \%$ & $101.1 \pm 2.9 \%$ & $100.4 \pm 3.0 \%$ \\
\hline
\end{tabular}

Each value shows the mean \pm S.D. $(n=4-5)$.

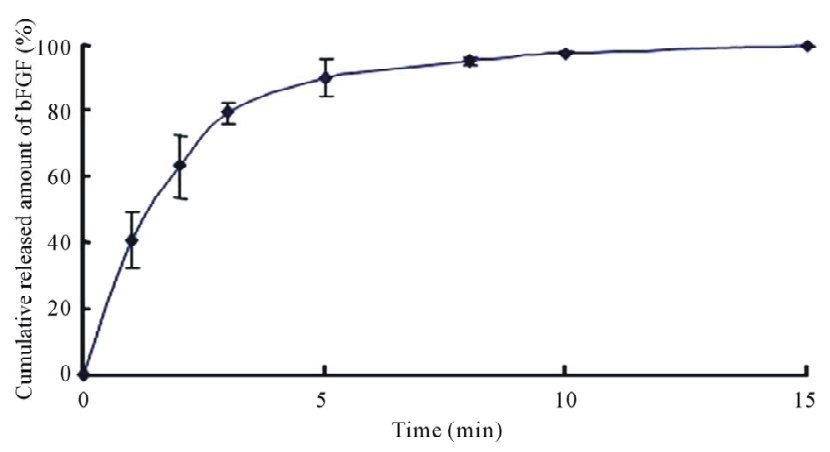

Figure 2. Dissolution profile of bFGF from array chip containing $2.0 \mu \mathrm{g}$ bFGF. Each point shows the mean \pm S.E. $(n=$ 3 - 5). 
performed in an experimental wound recovery model, where $5-6$ rats were used in each group. The typical results are depicted in Figure 3. When $2.0 \mu \mathrm{g}$ bFGF loaded DMs were administered to the rat skin wound, the wound had recovered well by $96 \mathrm{hr}$ after the start of the therapy, because a difference was found on the skin image of the treated rats against that of control group rats who were treated with placebo DM array chips. Similarly, wound recovery effects were observed with 1.0 and 0.5 $\mu \mathrm{g}$ bFGF loaded DMs. However, no wound recovery effect was detected when $0.1 \mu \mathrm{g}$ bFGF DM array chips were administered to the rat skin. Microscopic observation of bFGF DM treated wounds on day 28 after surgical operation was performed. DM treated wounds with 1.0 or $2.0 \mu \mathrm{g}$ bFGF loaded DM showed a marked decrease in granulation tissues formation after injury as compared to the control group as shown in Figure 4. A diagram in each figure shows the estimated dermal granulation tissue width. Azan staining, which is easy to discriminate the fibrotic region between injured and noinjured areas, intensifies the decreased granulation tissues following bFGF DM therapy.

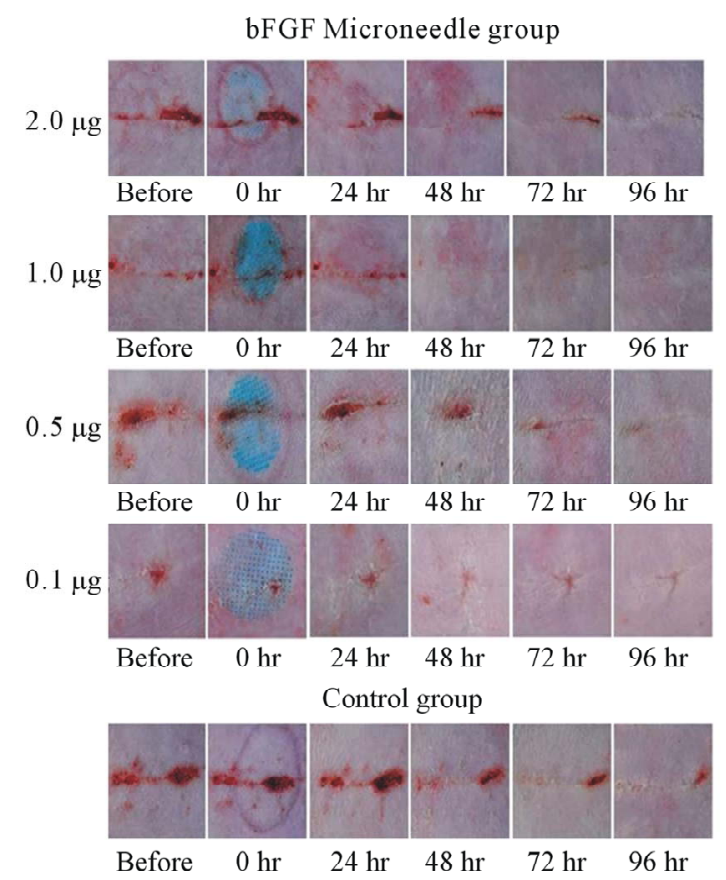

Figure 3. Experimental wound therapy by bFGF loaded DMs, 2.0, 1.0, 0.5 and $0.1 \mu \mathrm{g}$. One group consisted of 5 - 6 rats. The hair on the abdominal region was removed with a shaver. After wound was given by surgical knife, the skin was sutured with three dots and the abdominal skin was covered with tape. At 3 days after operation, bFGF loaded DM array chip was administered to the incisional wound formed on the abdominal skin and thereafter the state of the wound was monitored for 4 days and recorded. The active DM array chips groups received 2.0, 1.0, 0.5 and 0.1 $\mu \mathrm{g}$ of bFGF. The control group rats received placebo DM array chips.
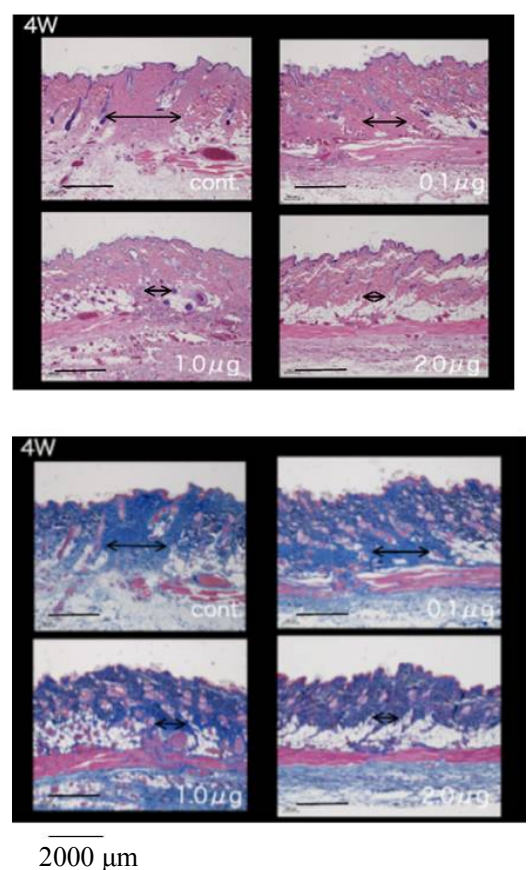

Figure 4. Histological study of the skin specimens at 4 weeks after the start of the therapy by bFGF DMs. A diagram line in each figure shows the estimated dermal granulation tissue width. Azan staining, which is easy to discriminate the fibrotic region between injured and no-injured areas, intensifies the decreased granulation tissues following bFGF DM therapy. Upper left photo shows the control group who receive placebo DMs, upper right photo shows $0.1 \mu \mathrm{g}$ bFGF DM group, lower left photo shows $1.0 \mu \mathrm{g}$ bFGF DM group and lower right photo shows $2.0 \mu \mathrm{g}$ bFGF DM group.

\subsection{Pharmacokinetics of bFGF in Systemic Circulation after Percutaneous Administration of bFGF Loaded DMs to Rat Skin}

Plasma bFGF levels vs. time curves after administration of 2.0 and $1.0 \mu \mathrm{g}$ bFGF loaded DMs to rat skin are presented in Figure 5. After the administration of bFGF loaded DM array chips, plasma bFGF levels did not increase as compared to the pre-dose levels. There were not significant differences on the plasma bFGF levels for $4 \mathrm{hr}$ between 2.0 and $1.0 \mu \mathrm{g}$ bFGF loaded DM groups and placebo DM group. To confirm whether systemic bFGF exposure occurred or not, bFGF solution was injected subcutaneously (sc) to rats at doses of 1.0, 2.0 and $10.0 \mu \mathrm{g}$ and the plasma bFGF level vs. time profiles are shown in Figure 6. Even for sc injection of bFGF at 2.0 $\mu \mathrm{g}$, plasma bFGF levels were almost equal levels to those of the placebo DM group. However, when the dose of bFGF was increased to $10.0 \mu \mathrm{g}$, the plasma bFGF level increased considerably to $68.5 \pm 14.0 \mathrm{pg} / \mathrm{ml}$ at $15 \mathrm{~min}$ after injection. Thereafter, the plasma bFGF level decreased to $10 \mathrm{pg} / \mathrm{ml}$ at $1 \mathrm{hr}$. Those results suggested that the systemic exposure of bFGF was not revealed after the 


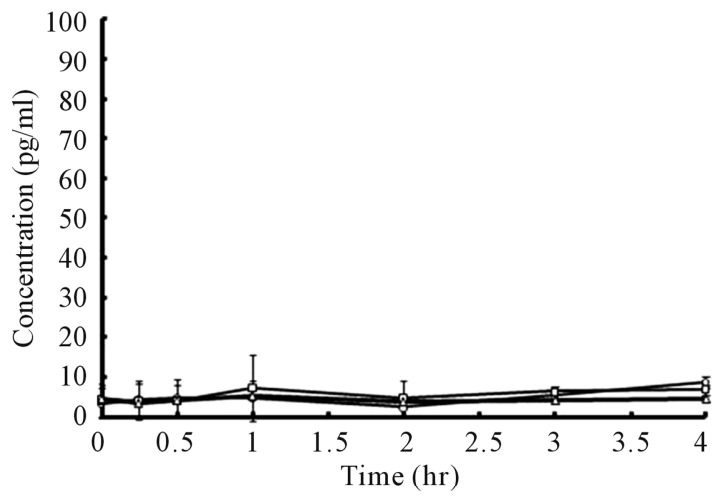

Figure 5. Plasma bFGF concentration vs. time curves after administration of bFGF loaded DMs to rat skin. $\circ: 1.0 \mu \mathrm{g}$ bFGF loaded DMs, $\square: 2.0 \mu \mathrm{g}$ bFGF loaded DMs, $\triangle$ : placebo DMs. Each point shows the mean \pm S.E. $(n=4)$.

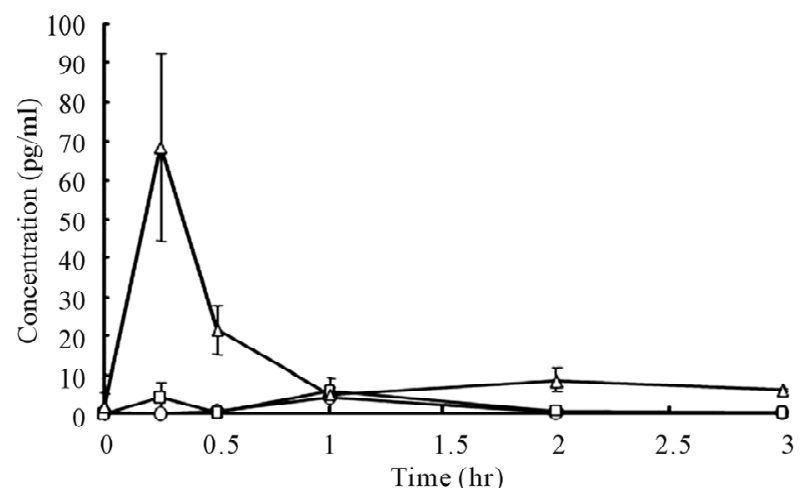

Figure 6. Plasma bFGF concentration vs. time curves after subcutaneous injection of bFGF solutions to rats. $\circ: 1.0 \mu \mathrm{g}$ bFGF, $\square: 2.0 \mu \mathrm{g}$ bFGF, $\triangle: \mathbf{1 0 . 0} \boldsymbol{\mu g}$ bFGF. Each point shows the mean \pm S.E. $(n=4)$

percutaneous administration of bFGF by DMs.

\subsection{Skin Tissue Kinetics of bFGF after Administration by DMs}

Because systemic exposure of bFGF was not detected, skin tissue levels of bFGF were assessed. The results are presented in Figure 7.

In the case of a $1.0 \mu \mathrm{g}$ bFGF-loaded DM array chip, the skin bFGF levels immediately after the administration of DMs were $264.2 \pm 56.5$ (SE) $\mathrm{ng} / \mathrm{g}$ wet weight. Thereafter, tissue bFGF levels decreased gradually and reached $105.1 \pm 27.4 \mathrm{ng} / \mathrm{g}$ wet weight at $6 \mathrm{hr}$ after administration. When a $2.0 \mu \mathrm{g}$ bFGF-loaded DM ray chip was administered to the rat skin, the tissue bFGF levels increased to $510.2 \pm 20.1 \mathrm{ng} / \mathrm{g}$ wet weight immediately after administration in proportional to the increase of the formulated amount of bFGF. The skin tissue bFGF level at $6 \mathrm{hr}$ after administration was $226.3 \pm 33.5 \mathrm{ng} / \mathrm{g}$ wet weight. To increase the tissue delivery of bFGF, the DM array chips were attached to the rat skin for $2 \mathrm{hr}$ after administration and tissue kinetics of bFGF was also

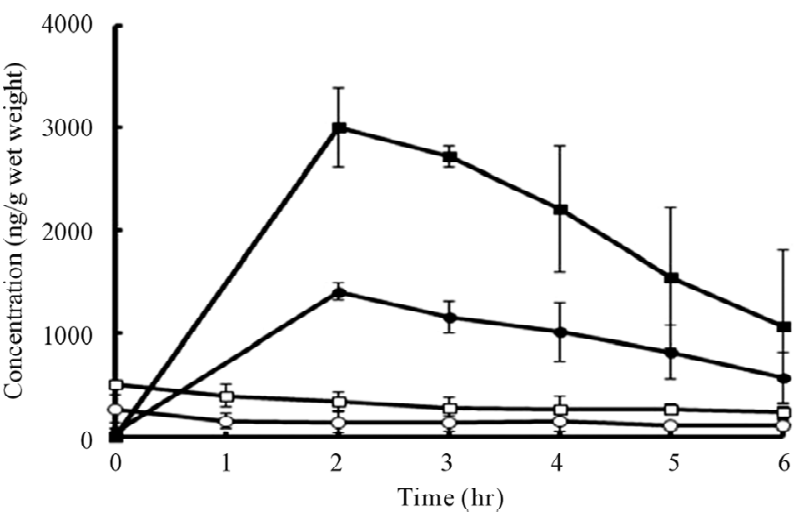

Figure 7. Skin tissue bFGF levels vs. time curves after application of 1.0 and $2.0 \mu \mathrm{g}$ bFGF loaded DMs array chips to rat skin for $3 \mathrm{~min}$ and $2 \mathrm{hr}$.

studied. In those cases, the tissue bFGF levels were increased considerably. The tissue bFGF levels at $2 \mathrm{hr}$ after administration were, respectively, $1410 \pm 40$ and 3003.1 $\pm 156.8 \mathrm{ng} / \mathrm{g}$ wet weight for $1.0 \mu \mathrm{g}$ and $2.0 \mu \mathrm{g} \mathrm{bFGF}-$ loaded DM array chips. Thereafter, the tissue bFGF levels decreased to $565.2 \pm 145.9$ and $1068.6 \pm 429.2$ $\mathrm{ng} / \mathrm{g}$ wet weight at $6 \mathrm{hr}$. Those results suggest that skin tissue delivery of bFGF was increased about 20 times by attaching the DM array chip to the skin for $2 \mathrm{hr}$.

\section{Discussion}

The bFGF and growth factors such as platelet-derived growth factor (PDGF), erythrocyte growth factor (EGF) and transforming growth factor $\beta$ (TGF- $\beta$ ) that localize at the wound site play a salient role in the wound healing process [22]. Among them, bFGF has many roles, not only in the early stage but also during the wound regeneration process. Especially, in an animal model experiment including steroid-treated mice and diabetic mice, the regeneration rate of the wound was prolonged [19-21, 23,24]. However, in these studies, bFGF was administered to mice by sc injection. In the case of human patients, wound repair on the face is an important intervention, where injection therapy is not sophisticated. Instead, displacement therapy must be developed to increase the QOL of the patients. Therefore, DMs are candidates to deliver bFGF to the epidermis and dermis of the skin. Because bFGF is a biopharmaceutical, protein, it is not stable $[25,26]$. However, in this study, lyophilized bFGF as a pharmaceutical preparation for the therapy of decubitus was used to prepare DMs. Results show that good long-term stability, 1 year, of bFGF was obtained even at $40^{\circ} \mathrm{C}$ in DMs. In this study, pharmacological evaluation of bFGF DM array chips was performed by an in vivo rat wound healing model experiment. At first, wound was made on the rat skin and was treated by suture. The bFGF therapy with DM array chips was performed at 3 days after wound was made 
when the sutures were removed. Therefore, the wound on the skin surface was healed and there was no worry that bFGF was absorbed into the skin through the wound. In the case of this wound healing model experiment, it was difficult to make score on the healing process of the skin wound.

With bFGF therapy, side effect, tumor, was suggested [27]. Therefore, we must take tumor risk into the consideration to develop a new percutaneous delivery system of bFGF. In fact, bFGF is used clinically in therapy of decubitus, where the clinical dose of bFGF is several hundred micrograms. Ishibashi et al. [28] conducted a clinical pharmacokinetic study of six patients with intractable skin ulcers by spraying bFGF solution. The bFGF solution concentration was $100 \mu \mathrm{g} / \mathrm{ml}$. Spraying of $0.3 \mathrm{ml}$ was performed five times for each treatment. Then, the administered dose of bFGF was $150 \mu \mathrm{g}$. In three patients, endogenous bFGF was detected in the systemic circulation before the administration of bFGF. However, serum bFGF concentrations were within the physiological variations during the treatment, from $30 \mathrm{~min}$ to 15 days after administration. In the remaining three patients, bFGF was not detected at any sampling point. In our experiment, two DMs containing 2.0 and $1.0 \mu \mathrm{g}$ bFGF and injection solutions containing 1.0 and $2.0 \mu \mathrm{g}$ bFGF were used, where significantly higher bFGF levels than endogenous bFGF levels were not detected in the systemic circulation. By assuming the mean body weight of these rats as $333 \mathrm{~g}$, the administered dose of bFGF, $1.0-2.0 \mu \mathrm{g}$, corresponds to $180-360 \mu \mathrm{g}$ of bFGF in a human with body weight assumed as $60 \mathrm{~kg}$. Therefore, systemic nonexposure of bFGF in rats after the sc injection and percutaneous administration with DMs were acceptable. However, high bFGF levels were maintained in the rat skin tissue. Immediately after the administration of $2.0 \mu \mathrm{g}$ bFGF loaded DMs, high skin tissue bFGF concentration was detected, $510.2 \pm 20.1 \mathrm{ng} / \mathrm{g}$ wet weight, at the administered rat skin site. Thereafter, the bFGF concentration declined gradually and reached $226.3 \pm 33.5 \mathrm{ng} / \mathrm{g}$ wet weight at $6 \mathrm{hr}$ after administration. When $1.0 \mu \mathrm{g}$ bFGF-loaded DM was administered to the rat skin, the initial bFGF level was $264.2 \pm 56.5 \mathrm{ng} / \mathrm{g}$ wet weight and skin tissue bFGF levels decreased, which matches the result obtained after the administration of $2.0 \mu \mathrm{g} b F G F$ loaded DMs. Therefore, good dose-dependency was found for the bFGF skin tissue kinetics. To measure the skin tissue bFGF levels, approximately $1.0 \mathrm{~g}$ of skin tissue was collected. By multiplying the skin tissue bFGF concentration immediately after the administration of bFGF loaded DMs by the tissue wet weight, the amount of bFGF administered to the skin can be estimated. In both cases, the estimated amounts of bFGF administered to the skin were approximately 500 and $250 \mathrm{ng}$. Because the bFGF contents in both DMs were 2.0 and $1.0 \mu \mathrm{g}$, about one-fourth of the loaded bFGF was inserted and administered to the rat skin. Tanaka et al. [29], after studying the mechanism of wound healing acceleration by bFGF, reported that bFGF promoted the recruitment of inflammatory cells into the wound site to induce a cascade reaction of growth factors including transforming growth factor- $\beta$ in a wound healing process. In their studies, $20 \mu \mathrm{l}$ of bFGF solution, $1.0 \mathrm{mg} / \mathrm{ml}$, was applied to the wound bed, ca. $2 \mathrm{~cm}^{2}$, and a transparent occlusive dressing was placed over the wound. Therefore, the administered dose of bFGF was $20 \mu \mathrm{g}$. Their experiment was designed to evaluate the topical bFGF preparation and extrapolate to the human decubitus therapy by bFGF spray preparation. The topically applied bFGF diffused into the epidermis and dermis and induced a cascade reaction of growth factors. In this study, on the other hand, bFGF was delivered directly to the epidermis by DMs. Therefore, bFGF affected the cascade reaction of growth factors more efficiently and wound healing effect was obtained with a smaller amount of bFGF, 2.0 $0.5 \mu \mathrm{g}$, loaded in the DMs [20].

For these studies, chondroitin sulfate was used as the base of DMs. Sun et al. studied the effect of dextran hydrogel scaffolds on the skin regeneration in burn wound healing models. Dextran hydrogel scaffolds showed enhanced angiogenic response and promoted skin regeneration [30]. In addition, hyaluronic acid was shown to be a potential vehicle for vitronectin: growth factor complexes in the two-dimensional monolayer cell cultures and 3D de-epidermized human skin equivalent models [31]. Chondroitin sulfate, dextran, and hyaluronic acid are polysaccharides used to prepare DMs as the base polymer. It was inferred that chondroitin sulfate might have a wound healing effect. Therefore, a wound healing experiment on placebo group DMs made of chondroitin sulfate was also performed. However, no significant difference was found in the healing effects between the placebo group and the control group, the non-treated group. Results show that bFGF DMs are a good delivery device for the local therapy of skin diseases.

\section{Conclusion}

The bFGF-loaded DMs were prepared and wound healing effects were studied after administration to hair-removed rat abdominal skin with DMs containing 2.0, 1.0, 0.5 , and $0.1 \mu \mathrm{g}$ bFGF. The 2.0, 1.0, and $0.5 \mu \mathrm{g}$ bFGFloaded DMs showed wound healing effects, but no difference was found between the wound healing effects of $0.1 \mu \mathrm{g}$ bFGF DMs and control groups. Pharmacokinetic study showed that there was not a systemic exposure by percutaneously administered bFGF with DMs and that the initial skin tissue bFGF concentrations were $510.2 \pm$ 20.1 and $264.2 \pm 56.5$ (SE) ng/g wet weight, which suggests that approximately $1 / 4$ of the loaded bFGF was administered to the rat skin. DMs are anticipated for use as 
a new system for delivering bFGF to patients via the skin.

\section{Acknowledgements}

This study was supported by a strategic fund of Ministry of Education, Culture, Sports, Science and Technology (MEXT) during 2008-2013 for establishing research foundations at private universities of Japan.

\section{REFERENCES}

[1] K. Takada, "Microfabrication Derived DDS: From Batch to Individual Production," Drug Discoveries and Therapeutics, Vol. 2, No. 3, 2008, pp. 140-155.

[2] Y. Ito, T. Nakahigashi, N. Yoshimoto, Y. Ueda, N. Hamasaki and K Takada, "Transdermal Insulin Application System with Dissolving Microneedles," Diabetes Technology and Therapeutics, Vol. 14, No. 10, 2012, pp. 891-899. doi:10.1089/dia.2012.0096

[3] K. Fukushima, A. Ise, H. Morita, R. Hasegawa, Y. Ito, N. Sugioka and K. Takada, "Two-Layered Dissolving Microneedles for Percutaneous Delivery of Peptide/Protein Drugs in Rats," Pharmaceutical Research, Vol. 28, No. 1, 2011, pp. 7-21. doi:10.1007/s11095-010-0097-7

[4] Y. Ito, R. Hasegawa, K. Fukushima, N. Sugioka and K. Takada, "Self-Dissolving Microarray Chip as Percutaneous Delivery System of Protein Drug," Biological and Pharmaceutical Bulletin, Vol. 33, No. 4, 2010, pp. 683690. doi: $10.1248 / \mathrm{bpb} .33 .683$

[5] Y. Ito, A. Saeki, K. Shiroyama, N. Sugioka and K. Takada, "Percutaneous Absorption of Interferon- $\alpha$ by Self-Dissolving Micropiles," Journal of Drug Targeting, Vol. 16, No. 3, 2008, pp. 243-249. doi:10.1080/10611860801902575

[6] H. S. Gill and M. R. Prausnitz, "Coated Microneedles for Transdermal Delivery," Journal of Controlled Release, Vol. 117, No. 2, 2007, pp. 227-237. doi:10.1016/j.jconrel.2006.10.017

[7] S. Henry, D. V. McAllis, M. G. Allen and M. R. Prausnitz, "Microfabricated Microneedles: A Novel Approach to Transdermal Drug Delivery," Journal of Pharmaceutical Sciences, Vol. 87, No. 8, 1998, pp. 922-925. doi:10.1021/js $980042+$

[8] G. Levin, A. Gershonowitz, H. Sacks, M. Stern, A. Sherman, S. Rudaev, I. Zivin and M. Phillip, "Transdermal Delivery of Human Growth Hormone through RF-Microchannels," Pharmaceutical Research, Vol. 22, No. 4, 2005, pp. 550-555. doi:10.1007/s11095-005-2498-6

[9] B. Barry and A. Williams, "Penetration Enhancers," Advanced Drug Delivery Reviews, Vol. 56, No. 5, 2004, pp. 603-618. doi:10.1016/j.addr.2003.10.025

[10] G. Cevc, "Lipid Vesicles and Other Colloids as Drug Carriers on the Skin," Advanced Drug Delivery, Vol. 56, No. 5, 2003, pp. 675-711. doi:10.1016/j.addr.2003.10.028

[11] A. Doukas, "Transdermal Delivery with a Pressure Wave," Advanced Drug Delivery, Vol. 56, No. 5, 2004, pp. 559579. doi:10.1016/j.addr.2003.10.031
[12] S. Mitragotri and J. Kost, "Low-Frequency Sonophoresis: A Review," Advanced Drug Delivery Reviews, Vol. 56, No. 5, 2004, pp. 589-601. doi:10.1016/j.addr.2003.10.024

[13] V. Preat and R. Vanbever, "Skin Electroporation for Transdermal and Topical Delivery," Advanced Drug Delivery Reviews, Vol. 56, No. 5, 2004, pp. 659-674. doi:10.1016/j.addr.2003.10.027

[14] S. E. Epstein, S. Fuchs, Y. F. Zhou, R. Baffour and R. Kornowski. "Therapeutic Interventions for Enhancing Collateral Development by Administration of Growth Factors: Basic Principles: Early Results and Potential Hazards," Cardiovascular Research, Vol. 4, No. 3, 2001, pp. 532542. doi:10.1016/S0008-6363(00)00217-0

[15] S. Hashimoto, A. Hagino and Y. Amagai, "Fibroblast Growth Factor-Induced Decrease in the Phosphorylation of Nsp100 Mediated through a Calcium-Dependent Mechanism and Blocked by Lectin," Cell Structure and Function, Vol. 15, No. 4, 1990, pp. 181-189. doi:10.1247/csf.15.181

[16] M. Okumura, M. Yajima, T. Nishimura, H. Ikeda and T. Nishimori, "General Pharmacology of Recombinant Human Basic Fibroblast Growth Factor," Arzneimittel Forschung, Vol. 46, No. 7, 1996, pp. 727-739.

[17] P. Rieck, M. Assouline, M. Savoldelli, C. Hartmann, C. Jacob, Y. Pouliquen and Y. Courtois, "Recombinant Human Basic Fibroblast Growth Factor (Rh-bFGF) in Three Different Wound Models in Rabbits: Corneal Wound Healing Effect and Pharmacology," Experimental Eye Research, Vol. 54, No. 6, 1992, pp. 987-998. doi:10.1016/0014-4835(92)90163-M

[18] R. Westermann, C. Grothe and K. Unsicker. "Basic Fibroblast Growth Factor (bFGF), a Multifunctional Growth Factor for Neuroectodermal Cells," Journal of Cell Science. Supplement, Vol. 13, 1990, pp. 97-117. doi:10.1242/jes.1990.Supplement 13.10

[19] Y. Akasaka, I. Ono, T. Kamiya, Y. Ishikawa, T. Kinoshita, S. Ishiguro, T. Yokoo and T. Ishii, "The Mechanisms Underlying Fibroblast Apoptosis Regulated by Growth Factors during Wound Healing," The Journal of Pathology, Vol. 221, No. 3, 2010, pp. 285-299. doi:10.1002/path. 2710

[20] I. Ono, Y. Akasaka, R. Kikuchi, A. Sakemoto, T. Kamiya, T. Yamashita and K. Jimbow, "Basic Fibroblast Growth Factor Reduces Scar Formation in Acute Incisional Wounds," Wound Repair and Regeneration, Vol. 15, No. 5, 2007, pp. 617-623. doi:10.1111/j.1524-475X.2007.00293.x

[21] I. Ono, "The Effects of Basic Fibroblast Growth Factor (bFGF) on the Breaking Strength of Acute Incisional Wounds," Journal of Dermatological Science, Vol. 29, No. 2, 2002, pp. 104-113. doi:10.1016/S0923-1811(02)00019-1

[22] G. R. Grotendorst, "Chemoattractants and Growth Factors," In: I. K. Cohen, R. F. Diegelmann, W. J. Lindblad, Eds., Wound Healing, W. B. Saunders Co., Philadelphia, 1992, pp. 237-246.

[23] Y. Akasaka, I. Ono, A. Tominaga, Y. Ishikawa, K. Ito and T. Suzuki, "Basic Fibroblast Growth Factor in an Artifi- 
cial Dermis Promotes Apoptosis and Inhibits Expression of Alpha-Smooth Muscle Actin, Leading to Reduction of Wound Contraction," Wound Repair and Regeneration, Vol. 15, No. 3, 2007, pp. 378-389. doi:10.1111/j.1524-475X.2007.00240.x

[24] Y. Akasaka, K. Ito, K. Fujita, K. Komiyama, I. Ono, Y. Ishikawa, Y. Akishima, H. Sato and T. Ishii, "Activated Caspase Expression and Apoptosis Increase in Keloids: Cytochrome C Release and Caspase-9 Activation during the Apoptosis of Keloid Fibroblast Lines," Wound Repair and Regeneration, Vol. 13, No. 4, 2005, pp. 373-382. doi:10.1111/j.1067-1927.2005.130404.x

[25] F. B. Anspach, H. Spille and U. Rinas, "Purification of Recombinant Human Basic Fibroblast Growth Factor: Stability of Selective Sorbents under Cleaning in Place Conditions," Journal of Chromatography A, Vol. 711, No. 1, 1995, pp. 129-139. doi:10.1016/0021-9673(95)00102-S

[26] S. Vemuri, I. Beylin, V. Sluzky, P. Stratton, G. Eberlein and Y. J. Wang, "The Stability of bFGF against Thermal Denaturation," Journal of Pharmacy and Pharmacology, Vol. 46, No. 6, 1994, pp. 481-486. doi:10.1111/j.2042-7158.1994.tb03831.x

[27] J. A. Wright and A. Huang, "Growth Factors in Mechanisms of Malignancy: Roles for TGF- $\beta$ and FGF," Histology and Histopathology, Vol. 11, 1996, pp. 521-536.

[28] Y. Ishibashi, M. Furue, K. Kikuchi, M. Fujimoto, K.
Takehara, S. Kawahara, M. Shirado, Y. Souma and M. Nindl, "Serum bFGF Concentrations Following Administration of KCB-1 in Patients with Intractable Skin U1cers," Journal Clinical Therapeutics and Medicines, Vol. 12, No. 10, 1996, pp. 2143-2158.

[29] E. Tanaka, K. Ase, T. Okuda, M. Okumura and K. Nogimori, "Mechanism of Acceleration of Wound Healing by Basic Bibroblast Growth Factor in Genetically Diabetic Mice," Biological and Pharmaceutical Bulletin, Vol. 19, No. 9, 1996, pp. 1141-1148. doi:10.1248/bpb.19.1141

[30] G. Sun, X. Zhang, Y. Shen, R. Sebastain, L. E. Dickinson, K. Fox-Talbot, M. Reinblatt, C. Steenbergen, J. W. Harmon and S. Gerecht, "Dextran Hydrogel Scaffolds Enhance Angiogenic Responses and Promote Complete Skin Regeneration during Burn Wound Healing," Proceedings of the National Academy of Sciences of the United States of America, Vol. 108, No. 52, 2011, pp. 20976-20981. doi:10.1073/pnas.1115973108

[31] Y. Xie, Z. Upton, S. Richards, S. C. Rizzi and I. David, "Leavesley, Hyaluronic Acid: Evaluation as a Potential Delivery Vehicle for Vitronectin: Growth Factor Complexes in Wound Healing Applications," Journal of Controlled Release, Vol. 153, No. 3, 2011, pp. 225-232. doi:10.1016/j.jconrel.2011.03.021 